\title{
Narcissistic Leadership and Workplace Deviance: A Moderated Mediation Model of Organizational Aggression and Workplace Hostility
}

\author{
Hussein Hurajah ALHASNAWI ${ }^{1}$, Ali Abdulhassan ABBAS ${ }^{2}$ \\ ${ }^{1}$ University of Kerbala, College of Administration and Economics, Business Administration Department, Kerbala, \\ Iraq, hussein.alhasnawi@uokerbala.edu.iq \\ ${ }^{2}$ University of Kerbala, College of Administration and Economics, Department of Accounting, Kerbala, Iraq, \\ ali.abd.alhassan@uokerbala.edu.iq
}

\begin{abstract}
Background: Workplace Deviance are among the most common phenomena observed in organizations. This might be attributed to narcissistic style of leadership and the manifestations of organizational aggression. It is further aggravated by increased workplace hostility. The main purpose of this research is to observe the impact of moderated mediation of organizational aggression and workplace hostility upon the relationship between narcissistic leadership and workplace deviance.

Methodology: A cross-sectional investigation was conducted using self-survey method. With 673 participants in the study, the author used an electronic questionnaire (Google Forms) to collect data from employees working at five food product companies in Iraq. Mediation model, moderation analysis, and moderated mediation models were evaluated using Structural Equation Modeling (SEM) for which AMOS V.23 software was used.

Results inferred that organizational aggression partially mediates a positive relationship between narcissistic leadership and workplace deviance. Further, the relationship between organizational aggression and workplace deviance depends on the changes in level of workplace hostility. Moreover, the study empirically supports the fundamentals of moderated mediation model. In other terms, the study infers that indirect effect of narcissistic leadership in workplace deviance through organizational aggression has been significantly moderated by workplace hostility. Conclusion: When leaders adopt narcissistic behaviors to achieve their personal interests, it leads to increased organizational aggression and workplace deviance that eventually increase the levels of workplace hostility. Accordingly, moderated mediation model provides a better understanding about how narcissistic leadership, organizational aggression, and workplace hostility all work together to influence workplace deviance.
\end{abstract}

Keywords: Narcissistic leadership, Organizational aggression, Workplace hostility, Workplace deviance

\section{Introduction}

Narcissistic leadership is one of the leadership styles in which the leader does not care about his followers whereas his or her only priority is to project himself. Such a leader possess characteristics such as arrogance, domination, hostility etc. (Aboramadan et al., 2021). Further, they create a hostile work environment among his or her follow- ers too (Redondo et al., 2017). As time passes by, the gap among the employees increases and the hostility in their workplace rises to an unprecedented level which can be understood by organizational aggression and selfish behavior of the narcissistic leader (Yildiz \& Alpkan, 2015).

Narcissistic leaders bring specific groups of workers close to them and stay away from other groups (Fatfouta, 2019). This characteristic increases the organizational ag-

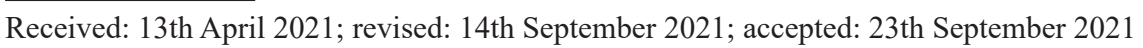


gression among groups and workers adopt aggressive behavior that harms other groups (Olson et al., 2006). Organizational aggression often originates from the groups that are close to the leader. Continuous arrogance and authoritarian behavior and partiality towards other groups who do not admire his or her behavior results in the development of a hostile work environment (Ghislieri et al., 2019). It negatively affects the creativity and leads to a decline in organizational loyalty, these consequences drive the workers to deviate from their workplace (Bowles \& Gelfand, 2010). Because the employees feel they are treated unequally, and loss of harmony and compatibility between the leader and rest of the employees create an unrest in the organization (Nevicka et al., 2013).

Employees who are loyal to the narcissistic leader are the first ones to implement deviance in their work environment. This phenomenon occurs since such employees feel that they are supported by the leader (Rahman et al., 2018; Judge et al., 2006a). This motivates other groups to get drawn towards the workplace deviance behavior, because they feel unfair treatment is rendered to them in a hostile work environment (Rosenthal, 2006). The employees further feel pushed towards deviation in the workplace and express it as an aggressive behavior against the behavior of narcissistic leader (Burton \& Hoobler, 2011) Who always seeks to achieve his self-interest rooted in his self-egomaniacal belief (Aboramadan et al., 2021) In this case, thoughts of deviation and aggression rising due to the leader narcissism, and the subsequent harmful behaviors of the followers (Tiwari \& Jha, 2021).

Based on the previous studies, there is a need arise here to conduct more studies on the relationship among narcissistic leadership, and aggressive and deviant behaviors in the workplace (Michel \& Bowling, 2013) add to that and after reviewing the literature concerning narcissistic leadership, we found only one study, which examined the links between leader narcissism and workplace deviance (Judge et al., 2006a). On the other hand, escalation effects of the narcissism in creating aggressive behaviors in the work environment and the exacerbation of its effects on the career level (Li et al., 2016). It is also very important to understand the causes of deviant behaviors in the food industry and the resulting frustration and exhaustion at work, and to determine their future treatments. (Jacinto et al., 2009). The need for current research is evident through increasing adoption of leaders to narcissistic traits that stimulate emergence of deviant and hostility behaviors among employees in the industrial sector and to diagnose their effects on performance. The current research work refers to a number of scientific contributions that established the relationship between the above-mentioned variables by adopting moderated mediation model among food product companies in Iraq. The current research work has a framework to achieve achieving four goals which are given herewith; first is to diagnose the extent of link between narcissistic leadership, organizational aggression, and hostility in the workplace with that of the workplace deviance. The second goal is to examine whether organizational aggression mediates the relationship between narcissistic leadership and workplace deviance. The third goal is to ascertain the moderated role played by workplace hostility in the relationship between organizational aggression and workplace deviance. Fourth goal is to understand the impact of narcissistic leadership on workplace deviance through organizational aggression conditions on increasing levels of workplace hostility.

\section{Theoretical Background}

\subsection{Narcissistic leadership}

Narcissism is a personality trait that includes grandiosity, arrogance, aggression, loss of self and entitlement, fragile self-respect, and hostility towards others (Fatfouta, 2019). Narcissistic leaders possess leadership beliefs and styles which are generally motivated by their needs for power and admiration, rather than emotional concern for components and organizations which they lead (Rosenthal, 2006). Narcissistic leaders feel that they must rely on themselves rather than others to satisfy their needs of life. They fake self-sufficiency (Nevicka et al., 2013; Huang et al., 2020). In narcissistic leadership, leaders' actions are primarily driven by their selfish needs and beliefs. Narcissistic personality is a great sense of self-importance, preoccupied with illusions of unlimited success and power, excessive need for admiration, envy, inferiority, and hypersensitivity (Fatfouta, 2019). It also leads to excessive self-centered behavior, manipulation, lack of empathy, and exploitation of others. Moreover, these aspects may translate into a competitive and unreliable climate which negatively affects the organizational culture (Ong et al., 2016). Narcissistic leaders like to be in professional environments that allow their narcissism to thrive, they look for organizations that tolerate their narcissistic traits. If an organization does not appreciate these traits, they avoid such organizations with flourishing cultures that are mission-focused (Anderson et al., 2007). Further, they look for hostile environments for their narcissism to thrive (Hellmich \& Hellmich, 2019). These characteristics make narcissists more inclined towards leadership positions. It ultimately results in negative consequences, in terms of decreased support, for follower's professional growth and poor work quality (Ghislieri et al., 2019).

\subsection{Organizational aggression}

Organizational aggression is defined as a behavior exhibited by a person who intends to harm another party. It is similar to chronic stress in the workplace which results in a state of panic, psychological and emotional stress in 
the organization (Ersan, 2020). Aggression is highly dangerous if it is issued by the leadership towards specific categories of employees (Hershcovis \& Barling, 2010). Aggression behaviour can be understood through intentional harming of one or more persons or even the organization. It may involve personal aggression too, driven by factors within the organization (Wittmer et al., 2013). Aggression within organizations may have several causes such as type of leadership and the approximation of some employees while rejecting other categories. This scenario creates aggression and workplace deviance for some groups from the right path, especially those employees who are close to the leader (Bryant \& Smith, 2001). In the United States of America and Europe, researchers estimated that organizational aggression costs organizations billions of dollars annually. These costs include direct costs such as workers' compensation, and indirect costs such as employee withdrawal behaviors or shareholder depreciation (Olson et al., 2006).

Aggressive behavior can otherwise be detailed as an individual or group social interaction that intends to harm the group or the company. There are two types of aggressions present such as emotional and reactive or vengeful aggression. While the latter occurs as a response to provocation and the former includes the means or directed towards a goal or predation (Bushman \& Anderson, 2001).

A number of classifications and dimensions of aggression has been suggested so far. Aggression may be in kind of forms such as verbal or physical, whether or not harm is intended to others and whether it is actively carried out or expressed negatively (Ramirez \& Andreu, 2006). The classification may also include emotions associated with aggression (such as anger) and mental states (such as impulsivity and hostility) while aggression may occur in response to social and antisocial factors (Ersan, 2020).

\subsection{Workplace hostility}

Workplace hostility may include physical actions, such as standing close to an individual, blocking doorways, and turning around hallways, Workplace hostility may also include subtle, but equally-frightening behavior, such as exclusion of individuals (Dickmann \& Watson, 2017). Hostility of the workplace negatively affects innovation and results in reduced organizational loyalty, the employees tend to move towards workplace deviance due to inequality in such hostile environment. Such behaviour is characterized by uncertainty during when it becomes highly challenging to obtain accurate information in a timely manner (Calantone \& Di Benedetto, 1994). The risks of working in such hostile work environments reduce the employees' ability to cope up which eventually cause stress among the employees. This stress reduces the employees' levels of adaptation to their environment and makes them undergo a phase of psychological burnout, isolation and increased levels of stress (Vance et al., 2004). Likewise, gender discrimination at work also increases the stress and make work environment hostile in the form of usage of vulgar words when dealing with employees, deliberate rejection of the leadership towards specific groups, sexual harassment and the lack of treatment (Walker, 2018; Worley \& Worley, 2020). Workplace turns hostility when leadership acts in a determined and intended manner to make the employee resign in retaliation for some actions. For example, employers force employees to resign by imposing undue discipline, reducing working hours, reducing wages, or transferring the complaining employee to a remote workplace (Maneethai, 2019).

\subsection{Workplace deviance}

Workplace deviance can be defined as any behavior that violates the values and standards of a governing society (Fagbenro \& Olasupo, 2020). These values and standards may be known or unknown while the deviant act harms and damages others and their private and public properties (de Lara et al., 2007). Workplace deviance is a voluntary behavior that violates the organizational rules, it is adopted by an individual or a group of people who endanger the health of other employees or the organization (Bowles \& Gelfand, 2010). Workplace deviance behavior is understood through different forms such as extortion of money, abuse of position, sexual harassment, gross disobedience, acceptance of fraud, impersonation, distortion of employee records, and manipulation (Fagbenro \& Olasupo, 2020; Abbas \& Al Hasnawi, 2020). Workplace deviance is a global phenomenon that has begun to spread widely in the recent years. It includes the exploitation of the employee and resources of an organization to achieve personal or collective benefits in violation of honor and official regulations (Bennett \& Robinson, 2000).

Workplace deviance has multiple negative effects, the most important of which are loss of job integrity, robbing honor and neutrality of an employee and broken justice and equality between individuals and the groups (Robinson \& Bennett, 1995). When employees suffer from weak relationships with the leader and when they receive fewer resources, responsibilities, and results for the same job title for many years, their behavior is likely to turn negative which can be understood through their performance (Malik \& Lenka, 2018).

\subsection{Hypotheses development}

Nowadays, organizations undergo different challenges and crises who hinder the growth of the organization. These events may affect the behavior of the leader and subordinates in the organization (Yildiz \& Alpkan, 2015). Especially, when the leader has narcissistic char- 
acteristics, this growth hindrance reflects on the employees in the form of aggression (Jørstad, 1996). Therefore, tools with psychometric safeguards are needed to assess aggression, anger and hostility among aggressive leaders (Judge et al., 2006a). These variables indicate the intensity of aggression and violence committed by leaders towards their employees. These are highly essential and should be considered when designing specific and effective intervention programs for these groups of leaders (Redondo et al., 2017). Extremely high levels of a leader's narcissistic traits are often associated with significant social impairment, increased alcohol use, aggressiveness, and antisocial behavior (Semenyna, 2018). Leadership narcissism affects individuals' relationships within the work environment and provokes aggressive behavior for them to achieve self-gain (Michel \& Bowling, 2013). Therefore, narcissists aggress others once they feel that their ego is loomed up (Mousa et al., 2020). Also, workplace deviance may be a violation of laws, rules, and regulations that govern the relationship of individuals with each other and with that of the public or private organization (Fagbenro \& Olasupo, 2020). This deviation occurs due to several reasons, including employees' exposure to organizational aggression by their leader or by other groups that are loyal to the leader (Michel \& Bowling, 2013). When their interests conflict with other groups in the same workplace, this makes the workers resort to workplace deviance (Rahman et al., 2021; Rahman et al., 2020; Yildiz \& Alpkan, 2015). In addition, the lack of harmony between workers in the same organization increases ostracism and hostility between individuals, and they divide into groups that supports the leader or oppose them which is in conflict with them (Judge, 2006b). The narcissistic type of leader often reacts in an aggressive manner to negative opinions and criticism, which in turn is reflected in employee deviation (Mousa et al., 2020). In contrast, employees with negative work climates will be more inclined to morally disengage when they experience perceived narcissistic supervision and implement organizational deviance (Zhang et al., 2018). This gets reflected in low performance of the individuals, lack of commitment, and weak organizational loyalty. All these factors together cause workplace deviance, due to these negative behaviors (Alavosius, 2008).

Based on the above discussion, the following hypotheses are proposed.

Hypothesis 1: Narcissistic leadership positively affects organizational aggression.

Hypothesis 2: Organizational aggression positively affects workplace deviance.

Hypothesis 3: Narcissistic leadership positively affects workplace deviance.

Hypothesis 4: Workplace hostility positively affects workplace deviance.

Some researchers argue that the negative impact of narcissistic personality of the leader leads to an increase in organizational aggression among workers (Li et al., 2016; Redondo et al., 2017). This phenomenon is represented by physical aggressive behavior since a group of employees feel dejected by their leader, and they feel they are contemptuous of the leader which finally ends their deviation (Michel \& Bowling, 2013). Traits of narcissism also stimulate aggression, arrogance, and control over others (Rosenthal, 2006).

These characteristics encourage more workplace deviance (Malik \& Lenka, 2018). Especially if the narcissistic leader continue pressurizing the employees, it gets converted into aggression and is reflected by increased workplace deviance (Ghislieri et al., 2019). Negative work conditions increase aggression among workers. If a hostile environment is available, it is considered as a predisposing factor for organizational aggression. This situation may develop further, and becomes highly dangerous and turns into quarrel and attacks in the work environment (Posthuma et al., 2019). The leader's negative behavior and increased practicing of psychological terror towards employees leads to an increase in organizational aggression. It turns into a violent phase of systematic attack against colleagues or subordinates (Godhardt, 2017). and this effects increase with the hostile climates of the work environment, such as poor relations with colleagues and weak cooperation in completing tasks (Greitemeyer \& Sagioglou, 2017). The individual leaves the organization or reaches a state in which he or she could not practice the profession and lose commitment to it which also drives him or her towards deviance (Krsnik Horvat \& Pagon, 2012). The arrogant and selfish behavior of the narcissistic leader may contribute in the creation of increased organizational aggression among workers. All of these qualities turn the organization dysfunctional, influence workers not to be committed towards the organization's goals and mission and search for their personal interests. The hostility of the work environment increases further and results in lower performance. Finally, most workers exhibit workplace deviation in their behavior and functioning (Goldman, 2009). Based on the above discussion, the following hypotheses are proposed.

Hypothesis 5: Organizational aggression mediates the relationship between narcissistic leadership and workplace deviance.

Hypothesis 6: Workplace hostility moderates the relationship between organizational aggression and workplace deviance.

Hypothesis 7: There is an indirect effect of narcissistic leadership in the workplace deviance of organizational aggression conditional on increased workplace hostility.

Based on the above hypotheses, the conceptual model shown in Figure 1 is proposed. 


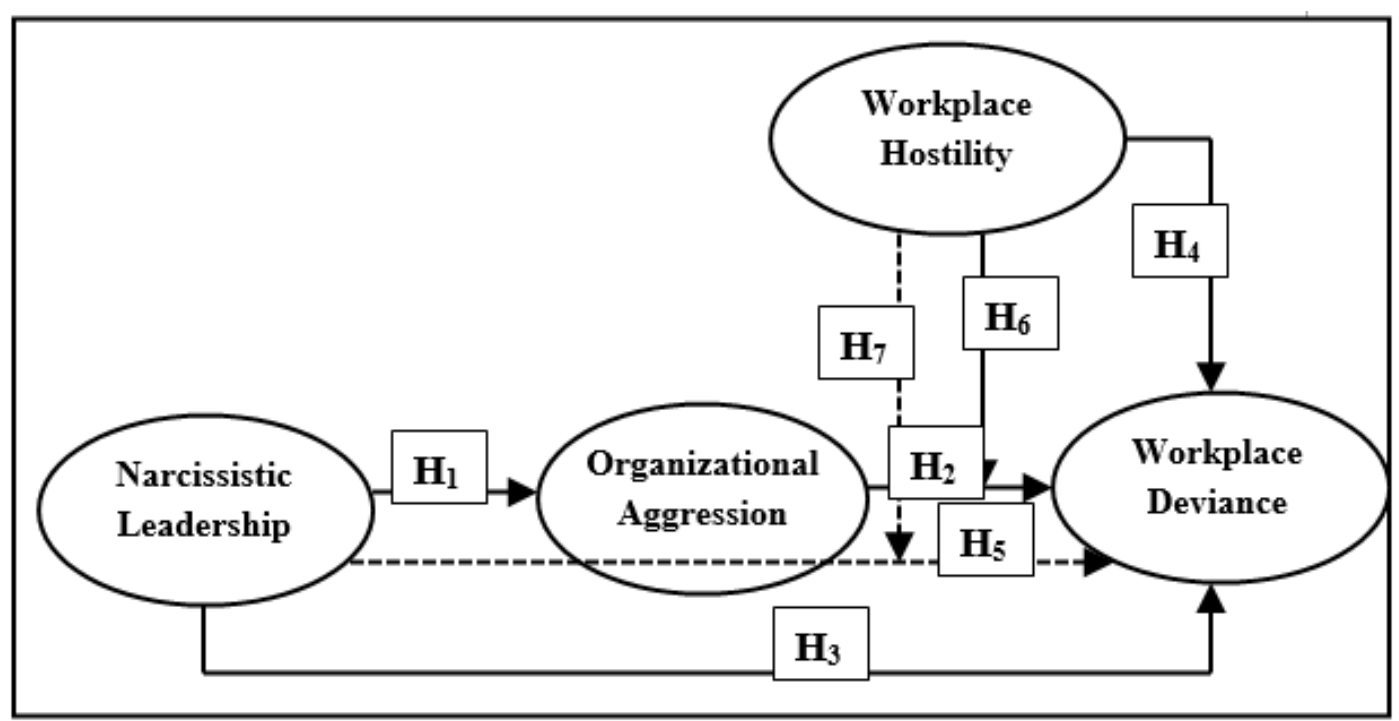

Figure 1: The conceptual model of research

\section{Methodology}

\subsection{Sample and data collection}

Food production sector in Iraq was chosen as the study setting since it has a heavy role in influencing the lives of citizens and it is important in the economic growth of the country. The data was collected in September 2020 by randomly selecting employees who work in five food product companies under different departments such as administration, technical, marketing and production. Online data was collected through questionnaire using google forms. A total of 673 completed questionnaires was selected for

Table 1: No. of samples collected from each company

\begin{tabular}{|c|c|}
\hline Company name & $\begin{array}{c}\text { Number of filled } \\
\text { questionnaire }\end{array}$ \\
\hline The General Co. for Food Products & 204 \\
\hline Tariq Food Products Co. & 81 \\
\hline Etihad Food Industries Co. Ltd. & 174 \\
\hline Advanced Foodstuff Industrial Co. & 122 \\
\hline Yafa Co. foods industries & 92 \\
\hline Total Sample & 673 \\
\hline
\end{tabular}

\subsection{Measures}

Narcissistic leadership: This variable is measured on the basis of (Fung et al., 2019). The measure included four sub-dimensions: Entitlement / exploitativeness (EE) statistical analysis which represent $39 \%$ of the total population. Unfilled and partially-filled questionnaires were ignored for further analysis. The staff were given 10 days to complete the survey. Table 1 illustrates the distribution of sample among the companies under study.

Among the study population, $5 \%$ of the participants hold a higher degree, whereas $69 \%$ people completed their university studies whereas rest of the proportion remain on hold a high school degree. Out of the total samples, males were $(64 \%)$ whereas females were $(36 \%)$. The ages of the respondents were in the range of (21) to (63) years. In terms of nature of activity, (48\%) workers function under production department while the remaining $(52 \%)$ people work in administrative and technical departments.
4 items, Authority / Leadership (AL) 4 items, Superiority / Arrogance (SA) 4 items, and Self-admiration / Self-absorption (SS) 4 items.

Organizational Aggression: This variable is calculated on the basis of (Bryant \& Smith, 2001) and includes four dimensions such as Physical Aggression (PA) 9 items, Verbal Aggression (VA) 5 items, Anger (AN) 7 items, Hostility (HO) 8 items.

Workplace Hostility: This variable is measured on the basis of (Selden \& Downey, 2012) and includes three dimensions: Interference with Work (IWW) 14 items, Denigration (DE) 11 items, Exclusion (EX) 5 items.

Workplace deviance: This measure was adopted from (Bennett \& Robinson, 2000) and includes two dimensions namely, Interpersonal Deviance (ID) 7 items and Organizational Deviance (OD) 12 items. 


\section{Data analysis and results}

\subsection{Confirmatory Factor Analysis (CFA)}

Confirmatory Factor Analysis (CFA) confirm the existence of a relationship between dimensions and items. Further, it ensures that the items do not go to all dimensions and every dimension is represented by a clear and appropriate number of non-measured items (Al Hasnawi \& Abbas, 2020). When performing CFA analysis for four variables, it becomes clear whether The Standards Load- ings of all items are acceptable and exceeds the ratio of 0.40 (Holtzman \& Sailesh, 2011). The values were found to be significant since the critical ratio for them were significant values, as shown in Table 2. Structural models for variables has a high degree of fit and, and values of the Compound Reliability coefficient has exceeded (0.7). the values of the Average Variance Extracted (AVE) for the variables were good and exceeded (0.50) (Hair et al, 2017), as shown in Table 3. Table 4 shows Cronbach's Alpha, descriptive statistics and the correlation coefficient among the variables.

Table 2: The Standard Loadings, Critical Ratios for Measurement model

\begin{tabular}{|c|c|c|c|c|c|c|c|c|c|c|c|}
\hline \multicolumn{3}{|c|}{ Narcissistic Leadership } & \multicolumn{3}{|c|}{ Organizational Aggression } & \multicolumn{3}{|c|}{ Workplace Hostility } & \multicolumn{3}{|c|}{ Workplace Deviance } \\
\hline Items & Loading & $\begin{array}{c}\text { Critical } \\
\text { Ratio }\end{array}$ & Items & Loading & $\begin{array}{c}\text { Critical } \\
\text { Ratio }\end{array}$ & Items & Loading & $\begin{array}{c}\text { Critical } \\
\text { Ratio }\end{array}$ & Items & Loading & $\begin{array}{c}\text { Critical } \\
\text { Ratio }\end{array}$ \\
\hline EE1 & .602 & 5.448 & PA1 & .561 & $* * *$ & IWW1 & .786 & 9.032 & ID1 & .885 & 7.387 \\
\hline EE2 & .578 & 5.273 & PA2 & .796 & 7.500 & IWW2 & .802 & 10.107 & ID2 & .912 & 5.882 \\
\hline EE3 & .791 & 6.925 & PA3 & .802 & 7.507 & IWW3 & .894 & 5.832 & ID3 & .726 & $* * *$ \\
\hline EE4 & .632 & $* * *$ & PA4 & .600 & 6.898 & IWW4 & .961 & 7.174 & ID4 & .671 & 6.135 \\
\hline AL1 & .758 & $* * *$ & PA5 & .776 & 7.788 & IWW5 & .954 & 6.180 & ID5 & .634 & 6.688 \\
\hline AL2 & .584 & 5.989 & PA6 & .731 & 6.226 & IWW6 & .654 & 6.627 & ID6 & .817 & 5.864 \\
\hline AL3 & .842 & 9.108 & PA7 & .689 & 5.243 & IWW7 & .863 & $* * *$ & ID7 & .662 & 5.255 \\
\hline AL4 & .763 & 6.953 & PA8 & .510 & 4.317 & IWW8 & .629 & 6.514 & OD1 & .695 & 8.286 \\
\hline SA1 & .544 & 5.692 & PA9 & .979 & 5.001 & IWW9 & .662 & 6.653 & OD2 & .810 & 8.738 \\
\hline SA2 & .619 & 5.679 & VA1 & .793 & $* * *$ & IWW10 & .680 & 7.564 & OD3 & .673 & $* * *$ \\
\hline SA3 & .822 & 9.175 & VA2 & .792 & 5.612 & IWW11 & .808 & 7.213 & OD4 & .762 & 7.583 \\
\hline SA4 & .789 & $* * *$ & VA3 & .649 & 5.338 & IWW12 & .722 & 7.210 & OD5 & .704 & 8.357 \\
\hline SS1 & .764 & 4.446 & VA4 & .753 & 5.162 & IWW13 & .692 & 8.322 & OD6 & .756 & 7.490 \\
\hline SS2 & .741 & 7.407 & VA5 & .646 & 5.318 & IWW14 & .954 & 6.808 & OD7 & .782 & 6.380 \\
\hline SS3 & .933 & 8.332 & AN1 & .679 & 5.495 & DE1 & .802 & 6.940 & OD8 & .679 & 6.354 \\
\hline \multirow[t]{15}{*}{ SS4 } & .678 & $* * *$ & AN2 & .565 & $* * *$ & DE2 & .704 & $* * *$ & OD9 & .645 & 7.380 \\
\hline & & & AN3 & .766 & 7.107 & DE3 & .464 & 5.424 & OD10 & .892 & 6.323 \\
\hline & & & AN4 & .698 & 5.555 & DE4 & .648 & 7.344 & OD11 & .616 & 5.964 \\
\hline & & & AN5 & .723 & 7.728 & DE5 & .796 & 7.108 & OD12 & .663 & 5.289 \\
\hline & & & AN6 & .712 & 7.541 & DE6 & .859 & 7.564 & & & \\
\hline & & & AN7 & .801 & 8.589 & DE7 & .851 & 6.307 & & & \\
\hline & & & HO1 & .876 & 7.541 & DE8 & .710 & 6.520 & & & \\
\hline & & & $\mathrm{HO} 2$ & .752 & $* * *$ & DE9 & .629 & 7.297 & & & \\
\hline & & & HO3 & .697 & 7.443 & DE10 & .761 & 9.412 & & & \\
\hline & & & $\mathrm{HO} 4$ & .743 & 7.960 & DE11 & .907 & 12.483 & & & \\
\hline & & & HO5 & .726 & 7.445 & EX1 & .837 & $* * *$ & & & \\
\hline & & & HO6 & .923 & 7.830 & EX2 & .870 & 13.992 & & & \\
\hline & & & HO7 & .538 & 6.621 & EX3 & .772 & 9.883 & & & \\
\hline & & & HO8 & .565 & 7.218 & EX4 & .722 & 8.645 & & & \\
\hline & & & & & & EX5 & .829 & 10.444 & & & \\
\hline
\end{tabular}




\subsection{Hypothesis testing}

\subsubsection{Test hypotheses of direct effect}

Direct effect hypotheses were tested based on regression analysis method using SPSS V.24 software. As shown in Table 5, a significant positive effect was observed between narcissistic leadership and organizational aggression $(\beta=.613, p<.01, \mathrm{R} 2=.376)$ and this result supports (H1). It is also evident from Table 5 that there is a significant effect of organizational aggression upon workplace deviance $(\beta=.541, \mathrm{p}<.01, \mathrm{R} 2=.292)$. Therefore, $(\mathrm{H} 2)$ is supported. A significant effect of narcissistic leadership is evident in workplace deviance $(\beta=.482, \mathrm{p}<.01, \mathrm{R} 2=$ .232) which supports (H3). A significant effect was found between workplace hostility and workplace deviance (= $.374, \mathrm{p}<.01, \mathrm{R} 2=.140$ ) due to which (H4) is supported.

\subsubsection{Hypothesis testing for mediating effect}

Figure 2 shows the structural model of mediating effect of organizational aggression upon the relationship between narcissistic leadership and workplace deviance. It is evident from the figure that there is a direct and significant

Table 3: Fit indices, Discriminant and convergent validity Indices for research variables

\begin{tabular}{|c|c|c|c|c|}
\hline $\begin{array}{c}\text { Fit Indices, Discriminant and conver- } \\
\text { gent validity Indices }\end{array}$ & $\begin{array}{c}\text { Narcissistic Lead- } \\
\text { ership }\end{array}$ & $\begin{array}{c}\text { Organizational } \\
\text { Aggression }\end{array}$ & $\begin{array}{c}\text { Workplace } \\
\text { Hostility }\end{array}$ & $\begin{array}{c}\text { Workplace } \\
\text { Deviance }\end{array}$ \\
\hline$\chi^{2}$ & 1089.312 & 933.845 & 1288.440 & 1108.220 \\
\hline CMIN/DF & 2.126 & 1.993 & 2.471 & 2.055 \\
\hline GFI & .925 & .908 & .914 & .919 \\
\hline CFI & .958 & .933 & .942 & .949 \\
\hline IFI & .963 & .938 & .947 & .954 \\
\hline TLI & .916 & .901 & .910 & .918 \\
\hline RMSEA & .060 & .076 & .068 & .056 \\
\hline Composed Reliability (CR) & 0.918 & 0.918 & 0.884 & 0.808 \\
\hline Average Variance Extracted (AVE) & 0.557 & 0.617 & 0.528 & 0.523 \\
\hline The Square Root (AVE) & 0.746 & 0.785 & 0.727 & 0.722 \\
\hline Maximum Shard Variance (MSV) & 0.376 & 0.376 & 0.376 & 0.376 \\
\hline Maximum Reliability MaxR(H) & 0.929 & 0.926 & 0.901 & 0.816 \\
\hline
\end{tabular}

Table 4: Cronbach's Alpha, Descriptive statistics, and the correlation coefficient

\begin{tabular}{|l|c|c|c|c|c|c|c|}
\hline Variables & $\alpha$ & $\mathrm{M}$ & SD & 1 & 2 & 3 & 4 \\
\hline 1. Narcissistic Leadership & .829 & 3.118 & .774 & 1 & & & \\
\hline 2. Organizational Aggression & .784 & 3.223 & .765 & $.613^{* *}$ & 1 & & \\
\hline 3. Workplace Hostility & .746 & 3.177 & .806 & $.483^{* *}$ & $.517^{* *}$ & 1 & \\
\hline 4. Workplace Deviance & .868 & 2.965 & .929 & $.482^{* *}$ & $.541^{* *}$ & $.374^{* *}$ & 1 \\
\hline
\end{tabular}

Table 5: Hypotheses testing for direct effect between the variables

\begin{tabular}{|c|c|c|c|c|}
\hline Regression Paths & $B$ & $t$ & $P$ & $R^{2}$ \\
\hline NarLea $>$ OrgAgg & $.613^{* *}$ & 20.113 & .000 & .376 \\
\hline OrgAgg $>$ WorDev & $.541^{* *}$ & 16.646 & .000 & .292 \\
\hline NarLea $>$ WorDev & $.482^{* *}$ & 14.256 & .000 & .232 \\
\hline WorHos $>$ WorDev & $.374^{* *}$ & 10.436 & .000 & .140 \\
\hline Notes: $n=673 .{ }^{* *} p<0.01$
\end{tabular}


impact created by narcissistic leadership upon workplace deviance $(\beta=.24, p<.01)$. As per Table 6 , the presence of an indirect impact of narcissistic leadership upon workplace deviance through the mediating role of organizational aggression $(\beta=.238, p<.01)$ is confirmed. With regards to the value of coefficient of determination $(\mathrm{R} 2=.332)$, narcissistic leadership and organizational aggression result in $(33 \%)$ of the changes that occur in workplace deviance. Thus, it is inferred that organizational aggression partially mediates the relationship between narcissistic leadership and workplace deviance. The study results supports (H5).

\subsubsection{Hypothesis testing for moderation effect}

From Figure 3, it is evident that the regression coefficient of interaction variable $(\beta=.29, \mathrm{p}<.01)$ is a significant value through (R2) value as shown in Table 7 . It is evident from the figure that the first regression model reached explanatory ability $(\mathrm{R} 2=.258)$ and the second regression model $(\mathrm{R} 2=.371)$ was attained. This indicates a positive difference between two models in (R2) value that reaches the (Change of $\mathrm{R} 2=.113$ ). Further, this difference is due to the entry of interaction variable as third variable in second regression model. Through the application of effect size equation (f 2), it becomes clear that the workplace hostility, by interacting with organizational aggression, resulted in workplace deviance and it reached (.180) according to (Selya et al., 2012). Figure 4 shows the graph of interactive relationship among the research variables. Thus, the results support (H6).

\subsubsection{Moderated mediation model test}

The moderated mediation regression analysis determines whether workplace hostility increases the indirect effect of narcissistic leadership in workplace deviance through organizational aggression at the companies under study. Figure 5 and Table 8 show the parameters of for moderated mediation regression model. As a regression coefficient of interaction variable between organizational aggression and workplace hostility, in the presence of independent variable, narcissistic leadership $(\beta=.17, \mathrm{p}<.01)$ remained a significant value. The value of coefficient of

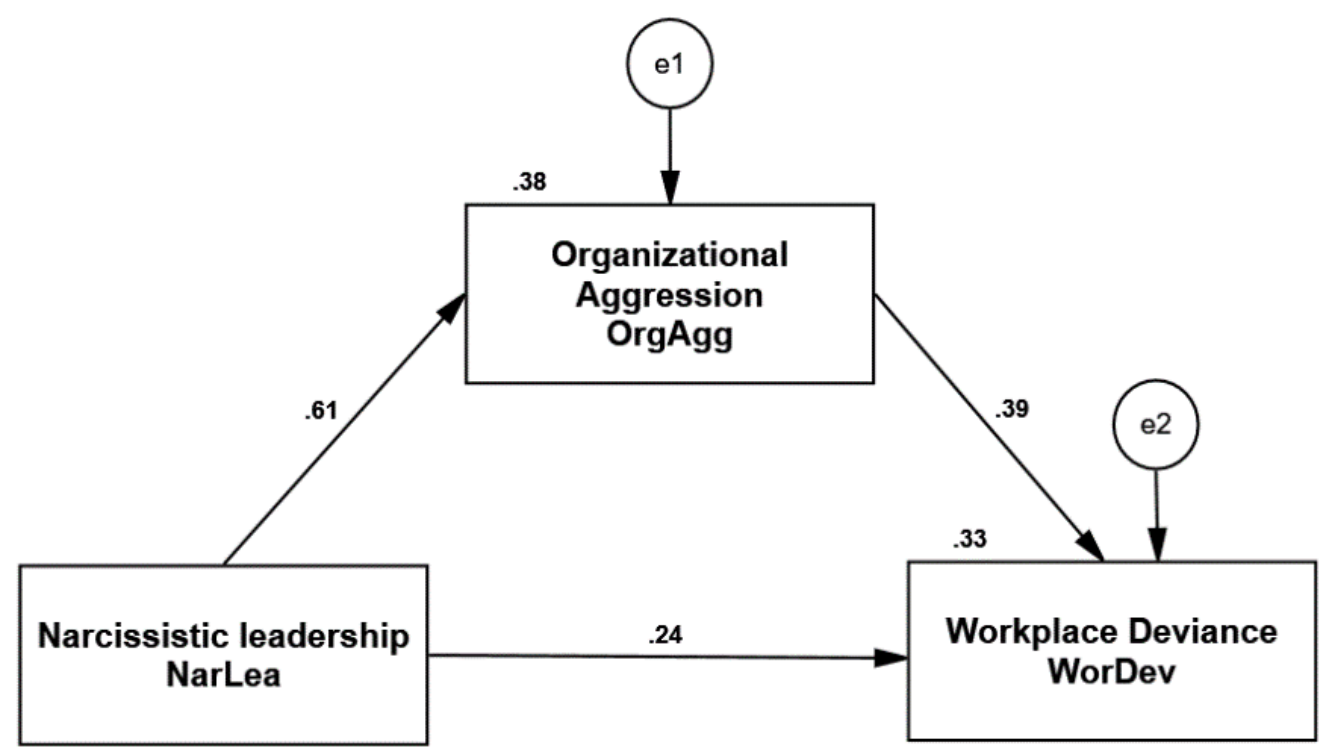

Figure 2: Hypothesis test of the mediating effect

Table 6: Hypothesis test parameters for mediating effect

\begin{tabular}{|c|c|c|c|c|}
\hline Regression Paths & Direct Effect & Indirect Effect & Total Effect & $R^{2}$ \\
\hline NarLea $\rightarrow$ WorDev & .241 & - & \multirow{2}{*}{.479} & .332 \\
\hline NarLea $\rightarrow$ OrgAgg $\rightarrow$ WorDev & - & .238 & & \\
\hline
\end{tabular}


determination $(\mathrm{R} 2=.38)$ was higher than its value in all existing regression models.

This proved the usefulness of the moderated mediation model. Three levels of standard deviation of the moderated variable were also tested for workplace aggression (low, medium, and high). The results showed that the negative impact of organizational aggression in workplace deviance tend to increase with workplace hostility levels. Through bootstrapping test, the conditional indirect effects of narcissistic leadership on workplace deviance through organi- zational aggression were examined at three different workplace hostility levels (low, medium, and high) as shown in Table 9. The results showed that conditional indirect effect increased, when the levels of workplace hostility increases. Thus, it has been proven that the moderated mediation model is significant $(\mathrm{p}=.0042)$ which confirms that the mediating effect has been moderated through workplace hostility. Thus, the current result supports (H7).

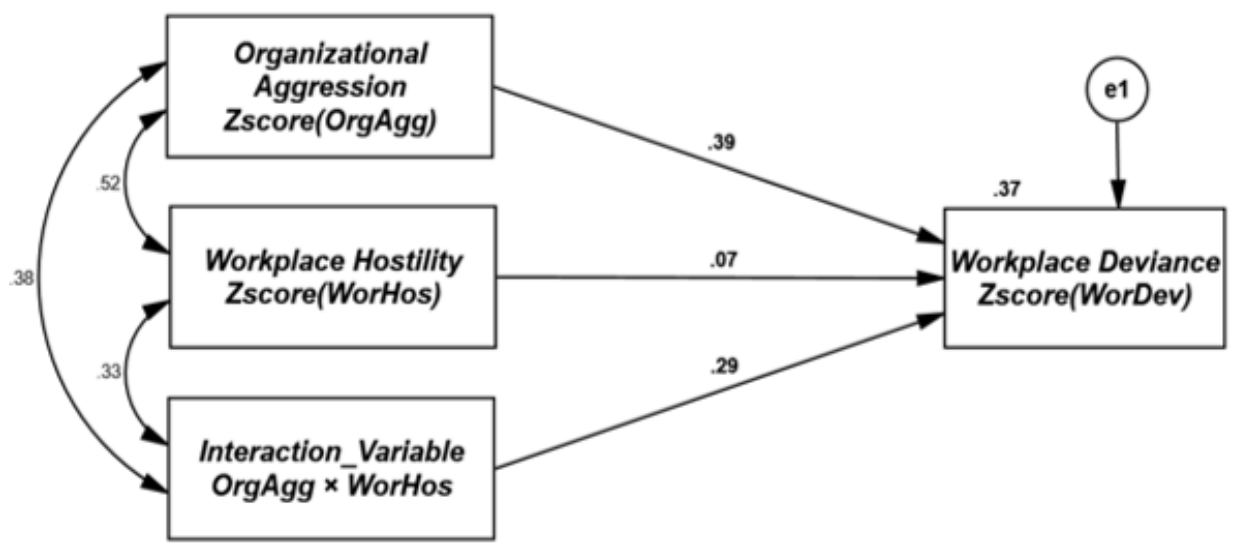

Figure 3: Hypothesis test of the moderated effect

Table 7: Hypothesis testing parameters for the moderated effect

\begin{tabular}{|c|c|c|c|c|c|}
\hline Regression Paths & Estimate & S.E. & C.R. & $P$ & $R^{2}$ \\
\hline ZOrgAgg $\rightarrow>$ ZWorDev & .394 & .037 & 10.664 & $* * *$ & Model 1 \\
\hline ZWorHos $\rightarrow$ ZWorDev & .074 & .036 & 2.051 & .040 & $R^{2}=258$ \\
\hline $\begin{array}{l}\text { Interaction Var. } \rightarrow \text { ZWorDev OrgAgg } \times \\
\text { WorHos }\end{array}$ & .243 & .028 & 8.544 & $* * *$ & $\begin{array}{l}\text { Model } 2 \\
R^{2}=.371\end{array}$ \\
\hline
\end{tabular}

\section{Discussion}

The results from hypothesis testing infer that narcissistic leadership has a direct impact on both organizational aggression and workplace deviance. This is embodied through narcissistic behaviors exhibited by the leader to achieve personal gain. But the phenomenon results in the emergence of some aggressive manifestations among employees (Rosenthal \& Pittinsky, 2006). Also, aggressive behavior of narcissistic leaders, when dealing with followers, leads to the emergence of a state of hatred and indifference between the leader and his followers. It fur- ther establishes a state of organizational aggression in the future (Jørstad, 1996). Such leaders fail to establish positive relationships with their followers in the organization. They leverage their skills to create a suitable work environment for their goals in which their self-interests can be attained (Higgs, 2009). Such leaders exhibit contradictory behaviors whose behaviors differ and negatively influence in the performance of their followers. This scenario results in aggression, workplace deviance, and inappropriate environment for work (Al Hasnawi \& Abbas, 2020).

It is also evident from hypotheses testing that there is a direct effect of organizational aggression upon workplace 
deviance. The deviation in job behavior indicates the existence of ethical crisis in behavior. This further can be understood through imbalance in values and deviations in attitudes. Mostly, it gets expressed through sound controls and standards that may be due to aggressive behaviors in work environment (Yildiz \& Alpkan, 2015). The employees who are exposed to aggression are likely to get dissatisfied or absent for their work or leave or change their jobs. Thus, the reduction in employee participation can be understood through their work performance which in turn increases the number of workplace deviance cases (Michel \& Bowling, 2013).

The results further infer that workplace hostility directly impacts the employees and induce workplace deviance. This phenomenon can be confirmed through interference with work, distortion of reputation, gossip, self-love and

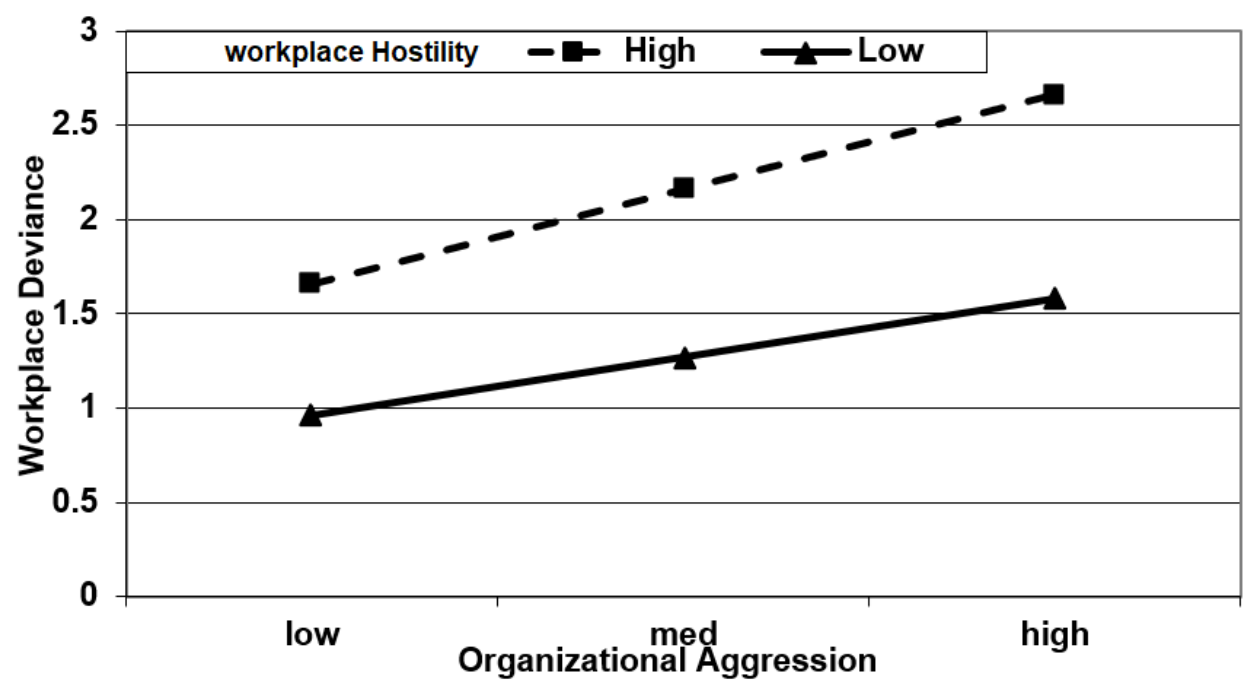

Figure 4: Moderated effect of workplace hostility upon relation between organizational aggression and workplace deviance

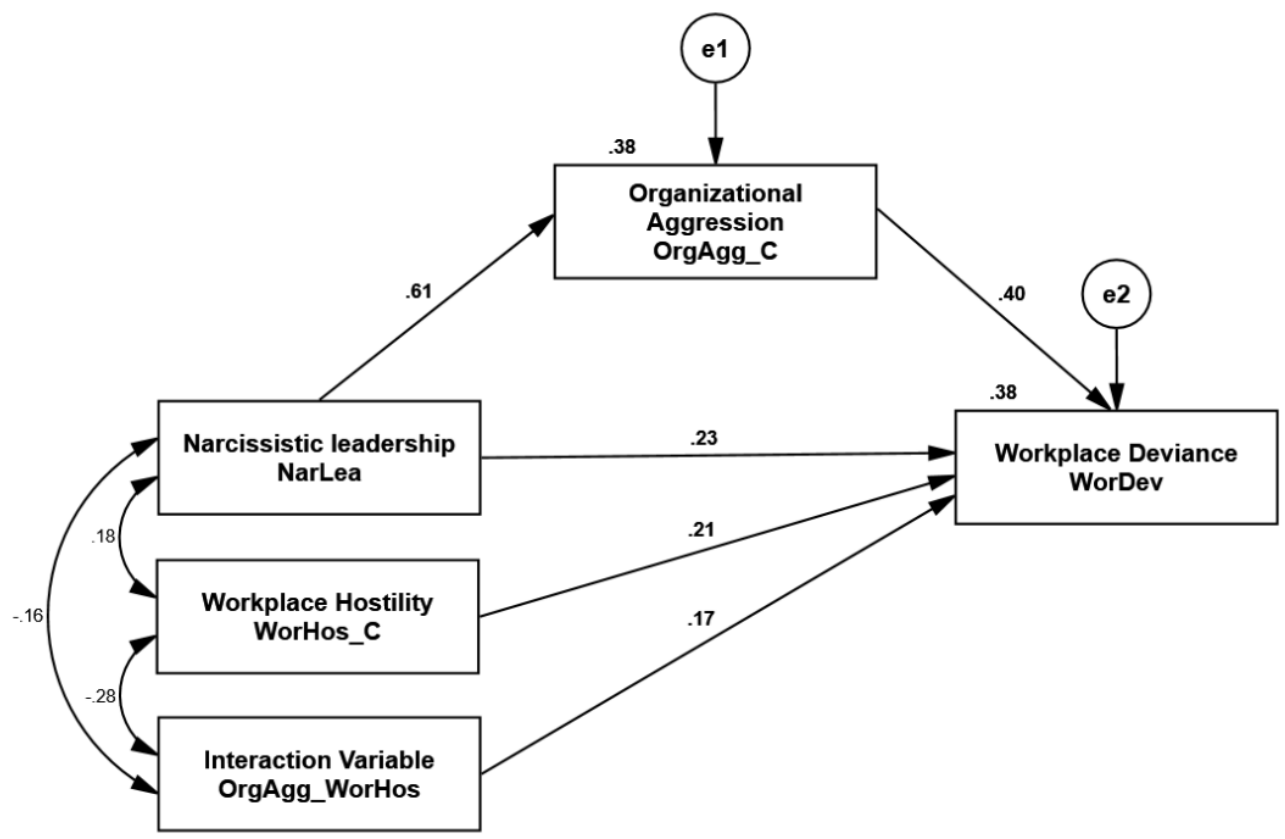

Figure 5: Hypothesis test of the moderated mediation effect 
Table 8: Parameters of hypothesis test of the moderated mediation effect

\begin{tabular}{|c|c|c|c|c|c|c|c|}
\hline \multicolumn{3}{|c|}{ Paths } & S.R.W. & Estimate & S.E. & C.R. & $P$ \\
\hline Narcissistic leadership & $\rightarrow$ & $\begin{array}{l}\text { Workplace } \\
\text { Deviance }\end{array}$ & .230 & .277 & .047 & 5.909 & *** \\
\hline Narcissistic leadership & $\rightarrow$ & $\begin{array}{c}\text { Organizational } \\
\text { Aggression }\end{array}$ & .613 & .607 & .030 & 20.128 & $* * *$ \\
\hline $\begin{array}{l}\text { Organizational } \\
\text { Aggression }\end{array}$ & $\rightarrow$ & $\begin{array}{l}\text { Workplace } \\
\text { Deviance }\end{array}$ & 396 & .481 & .047 & 10.316 & $* * *$ \\
\hline Workplace Hostility & $\rightarrow$ & $\begin{array}{l}\text { Workplace } \\
\text { Deviance }\end{array}$ & .207 & .132 & .020 & 6.500 & $* * *$ \\
\hline $\begin{array}{l}\text { Interaction Var. } \\
\text { OrgAgg×WorHos }\end{array}$ & $\rightarrow$ & $\begin{array}{l}\text { Workplace } \\
\text { Deviance }\end{array}$ & .170 & .093 & .017 & 5.346 & $* * *$ \\
\hline
\end{tabular}

Table 9: Bootstrapping test of the moderated mediation model

\begin{tabular}{|l|c|c|c|c|}
\hline \multicolumn{1}{|c|}{ Parameter } & Estimate & Lower & Upper & P \\
\hline Low_SS & .4069 & .3157 & .5021 & .0001 \\
\hline Med_SS & .4812 & .3772 & .5839 & .0001 \\
\hline High_SS & .5599 & .4576 & .6401 & .0000 \\
\hline Low_CIE & .2465 & .1396 & .3505 & .0001 \\
\hline Med_CIE & .2926 & .1989 & .3836 & .0001 \\
\hline High_CIE & .338 & .2198 & .4429 & .0000 \\
\hline Mod_Med & .045 & .0223 & .0694 & .0042 \\
\hline
\end{tabular}

(Low_SS , Med_SS, High_SS) Simple Slope ; (Low_CIE, Med_CIE, High_CIE) Conditional Indirect Effect; (Mod_Med) Hayes Index of Moderated Mediation.

self-preference over others. All these scenarios increase the employees' deviation at workplace (Alavosius, 2008). Also, behavioral patterns in hostile work environments of all kinds may lead to demeaning social behavior and silver gestures that increase employees' tendency to deviate (Gates, 2016). This may lead them to violate job rules and threaten the well-being of an organization (Rahman et al., 2017; Fagbenro \& Olasupo, 2020). The results also demonstrated that organizational aggression partially mediates the relationship between narcissistic leadership and workplace deviance. Thus, it is inferred that narcissistic leaders have high aggression rate as a result of their arrogance which can be understood from their aggressive behaviors towards others (Lee et al., 2013). Narcissistic leader may reach a stage in which he or she turns destructive to the organization by implementing excessive aggression at workplace and exhibit aggressive behaviors that push employees to deviate (Beugre, 2005). It is a dark side in organizational work that occurs mainly due to its leader. The consequences get reflected in the deviation of employees, due to aggressive behaviors in workplace (Baars, 2015).
The results further infer that workplace hostility moderates the relationship between organizational aggression and workplace deviance. The behavior of job delinquency arises from several aggressive factors spread across job environment. Its impact gets increased with absence of conscience, wrong family upbringing, weak supervision and disciplinary systems (Bowles \& Gelfand, 2010; Selden \& Downey, 2012). The employees exhibit laziness in completing the tasks and if done so, the tasks are improper and unfulfilled. This increases the deviations of the employee when they perform their duties related to regularity at work and behavioral, financial and criminal deviations (Bennett\& Robinson, 2000; Malik \& Lenka, 2018).

The hypotheses testing further established the role played by moderated mediation effect of the variables. The organizational aggression played a mediating effect in the relationship between narcissistic leadership and workplace deviance through workplace hostility. In other terms, the relationship between organizational aggression and workplace deviance was proved in the presence of independent variable. Narcissistic leadership increases with increasing 
level of hostility in the workplace. As the hostility of workplace increases, the negative factors in the organization also increase. For instance, the type of leadership that encourages and supports certain groups and aims at them to favor their personal interests. This contributes in providing such leaders a fertile ground for organizational aggression. Such situation turns the organization in a state of uncertainty, loss of stability and motivates the employees to deviate from workplace (Posthuma et al., 2019). Also, organizational aggression continues in the work environment as a result of leadership's failure to interfere in finding quick solutions. This occurs especially if the leadership is isolated from employees as in narcissistic leadership. Such leaders create barriers from their employees and often do not listen to them (Selden \& Downey, 2012). The competition among employees often creates a hostile work environment. This environment is mostly created by the leadership characterized by behavioral and social imbalance and those who prefer personal interest over public interest. This behaviors deviates the employees through aggression that may spread among them (Godhardt, 2017).

\section{Theoretical and Practical implications}

To our best knowledge, this is contribution to supplying literatures with a moderated mediation model of the relationship between narcissistic leadership and workplace deviation by mediating organizational aggression and by adopting workplace hostility as a moderator variable. The current study identified new insights on the level of administrative work regarding current variables. First, in general, the current study draws attention of the leaders of companies i.e., the sample considered for the study, towards the negative aspects included in study variables. It may appear in the workplace that narcissistic leaders are busy in proving their sufficiency, strength, beauty, stature and superiority. However, it is striking to know about the behavior of these individuals in terms of personal exploitation of followers and making them live under delusion resulting in workplace deviation during many times (Braun, 2017). Second, as per the study results, one of the most common reasons in the emergence of workplace deviance is the prevalence of hostility factors in work environment, especially in food industries and the companies under study. This findings necessitate that the leaders should pay attention to prevent interference in work and the destructive factors such as defamation, exploitation, exclusion and personal favoritism at work so that deviation can be avoided (Lyubykh et al., 2020).

Third, it turns out that organizational aggression mediates a positive relationship between narcissistic leadership and workplace deviance. Narcissistic leaders are self-absorbed, and can be distinguished by their aggressive tendencies under criticism. They tend to prove their selfworth by detracting from others which drives other individuals to deviate from the true course of action (Nevicka et al., 2018).

Fourth, this study found that workplace hostility increases the impact of organizational aggression on workplace deviance. The organizational aggression leads to the emergence of behavior that deviates from agreed standards to achieve special goals and objectives. This gets increased by hostility factors that spread from time to time in the work environment (De Lara, 2004). Fifth, this study contributed an in-depth understanding about the moderated mediation role. Further it also demonstrated the indirect effect of narcissistic leadership in workplace deviance through organizational aggression conditioned on increasing levels of workplace hostility. This proves the opinion that in many cases, due to narcissistic behaviors, leader adopts an aggressive environment in his dealings. This contradicts with the values and expectations of the employees in the organization which in turn results in the existence of hostile work climate. Such hostile climate negatively affects the employees through their actions and communications with their colleagues at work (Heathfield, 2014).

\section{Conclusions}

On the basis of experimental results attained from this study, it can be concluded that leadership narcissism is an indicator of functional deviation. A narcissistic leader achieves an increase in organizational aggression which in turn results in more deviation at personal and organizational level. Likewise, workplace hostility is an important factor that predicts the level of workplace deviance, especially with regard to interference in work and personal affairs by colleagues or by direct higher official. Workplace hostility continues with distortion of reputation, relationships, exceptions, and personal favoritism that gets justified for deviation and error in case if it spreads too.

On the basis of current study results, it can be concluded that the narcissistic behaviors of a leader, in their day-to-day activities, increase the aggressiveness of organizational environment in terms of persistence of employees against verbal and physical aggression and hostility behavior towards others. This becomes a reason for some to practice deviant behaviors in their workplace. Moreover, the study found that there is a relationship between organizational aggression and workplace deviance changes, according to the variations in the level of workplace hostility. This scenario has been proved at corporate level too. The study results mentioned that, in terms of negative factors, sometimes the aggressive behavior spreads in organizational and functional environment too and lend their shadows. The prevailing organizational climate clearly increased the impact of aggressive behaviors towards employee deviation at workplace. 
Based on the above results, the study draws attention to the indirect role of narcissistic leadership in workplace deviance through organizational aggression conditioned on workplace hostility. The study results leads to an important conclusion that the deviant behaviors of the employees are motivated at individual and organizational level with increase in the narcissism of leaders. This phenomenon occurs in terms of exploiting the efforts of individuals, admiring oneself, bullying others, arrogance, and the desire to accomplish victory at the expense of others that accentuate negative, unsupportive climates, tension, intimidation, sabotage at work and aggressive behavior. In organizational environment, whether public or private, there are increasing levels of workplace hostility observed these days in terms of increased work pressures, gossip, ostracism, harassment, interference in work, and organizational violations.

\section{Limitations and Future trends}

Despite the contributions of current study on addressing the identified gaps and the importance of relationships between study variables, there are some potential limitations related to this investigation as well. First, the study data was obtained from five organizations in the food industry. The generalizability of our results to rest of the industrial sectors is limited. So, this calls for implementation of current study model in other industries such as construction, textile, rubber industries, and service fields in future studies. Second, the study was conducted in private sector organizations and it did not include public sector organizations characterized by high workplace deviance due to huge number of employees and nature of prevailing structures. Third, since the adopted measures are based on self-report method, this raises the possibility of restricted results, due to difference in common method/source. Thus, future studies should consider in-depth reliability of multiple sources used in data collection.

The future directions of the current study are as follows: First, although the current study findings proved the moderated mediation role among the study variables, there is still room for more empirical research for these variables to determine other predictors of workplace deviance. Second, the current study intended to identify some indicators that correspond to workplace deviance. So, future studies should be conducted to identify other indicators that exert the same effect, for example negative relationship between the leader and the followers, ostracism in workplace, leader's contradictory behaviors, gossip at workplace, bullying behavior at work, and authoritarian leadership and so on. Third, it will be highly useful if future studies try to include some positive variables that reduce the level of workplace deviance. The future researchers may also adopt variables that reduce the negative effects of organizational aggression or workplace hostility such as trust, justice, organizational integrity, and positive leadership theories such as authentic, participatory and paternal leadership as positive functions to reduce the effect of negative variables considered in this study.

\section{Literature}

Abbas, A. A., \& Al Hasnawi, H. H. (2020). Role of Psychological Contract Breach and Violation in Generating Emotional Exhaustion: The Mediating Role of Job Procrastination. Management Letters. 1-14. http://hdl. handle.net/10810/49120

Al Hasnawi, H. H., \& Abbas, A. A. (2020). Workplace Ostracism as a Mediating Variable in the Relationship between Paradoxical Leader Behaviours and Organizational Inertia. Organizacija, 53(2), 165-181. https:// doi.org/10.2478/orga-2020-0011

Alavosius, M. P. (2008). Comments on "There's a Policy for That": Interdisciplinary Analyses of Hostile Work Environments. Behavior and Social Issues, 17(2), 182. https://doi.org/10.5210/bsi.v17i2.2348

Aboramadan, M., Turkmenoglu, M.A., Dahleez, K.A. \& Cicek, B. (2021), Narcissistic leadership and behavioral cynicism in the hotel industry: the role of employee silence and negative workplace gossiping, International Journal of Contemporary Hospitality Management, 33(2), 428-447. https://doi.org/10.1108/ IJCHM-04-2020-0348

Baars, Samira. (2015). Narcissistic leadership: The influence on followers' psychological well-being through Leader Member Exchange (LMX) quality, and the moderating role of follower narcissism, Master thesis, University of Amsterdam/ Department of Psychology, 1-104.

Bennett, R. J., \& Robinson, S. L. (2000). Development of a measure of workplace deviance. Journal of Applied Psychology, 85(3), 349. https://doi.org/10.1037/00219010.85.3.349

Beugré, C. D. (2005). Understanding injustice-related aggression in organizations: A cognitive model. The International Journal of Human Resource Management, 16(7), 1120-1136. https://doi. org/10.1080/09585190500143964

Bowles, H. R., \& Gelfand, M. (2010). Status and the evaluation of workplace deviance. Psychological Science, 21(1), 49-54. https://doi. org/10.1177\%2F0956797609356509

Braun, S. (2017). Leader narcissism and outcomes in organizations: a review at multiple levels of analysis and implications for future research. Frontiers in Psychology, 8, 773. https://doi:10.3389/fpsyg.2017.00773

Bryant, F. B., \& Smith, B. D. (2001). Refining the architecture of aggression: A measurement model for the Buss-Perry Aggression Questionnaire. Journal of Research in Personality, 35(2), 138-167. https://doi. 
org/10.1006/jrpe.2000.2302

Burton, J. P., \& Hoobler, J. M. (2011). Aggressive reactions to abusive supervision: The role of interactional justice and narcissism. Scandinavian Journal of Psychology, 52(4), 389-398. https://doi.org/10.1111/ j.1467-9450.2011.00886.x

Bushman, B. J., \& Anderson, C. A. (2001). Is it time to pull the plug on hostile versus instrumental aggression dichotomy? Psychological Review, 108(1), 273.

Calantone, R., \& Di Benedetto, C. A. (1994). How firms organize for successful innovation in a hostile environment. The Journal of Technology Transfer, 19(1), 1726. https://doi.org/10.1007/BF02373667

De Lara, P. Z. M., Tacoronte, D. V., \& Ting-Ding, J. M. (2007). Procedural justice and workplace deviance: The mediating role of perceived normative conflict in work groups. In Decisiones basadas en el conocimiento y en el papel social de la empresa: XX Congreso anual de AEDEM (p. 23). Asociación Española de Dirección y Economía de la Empresa (AEDEM).

Dickmann, M., \& Watson, A. H. (2017). "I might be shot at!" exploring the drivers to work in hostile environments using an intelligent careers perspective. Journal of Global Mobility, 5(4), 348-373. https://doi. org/10.1108/JGM-12-2016-0066

Ersan, C. (2020). Physical aggression, relational aggression and anger in preschool children: The mediating role of emotion regulation. The Journal of General Psychology, 147(1), 18-42. https://doi.org/10.1080/00 221309.2019.1609897

Fagbenro, D. A., \& Olasupo, M. O. (2020). Quality of Family Life and Workplace Deviant Behaviour with Perceived Competence as a Mediator among University Staff. Naše gospodarstvo/Our economy, 66(2), 1527. https://doi.org/10.2478/ngoe-2020-0008

Fatfouta, R. (2019). Facets of narcissism and leadership: A tale of Dr. Jekyll and Mr. Hyde?. Human Resource Management Review, 29(4), 100669. https://doi. org/10.1016/j.hrmr.2018.10.002

Fung, H. G., Qiao, P., Yau, J., \& Zeng, Y. (2020). Leader narcissism and outward foreign direct investment: Evidence from Chinese firms. International Business Review, 29(1), 101632. https://doi.org/10.1016/j.ibusrev.2019.101632

Gates, T. G. (2016). Hostile Work Environment in the United States. The Wiley Blackwell Encyclopedia of Gender and Sexuality Studies, 1-2. https://doi. org/10.1002/9781118663219.wbegss514

Ghislieri, C., Cortese, C. G., Molino, M., \& Gatti, P. (2019). The relationships of meaningful work and narcissistic leadership with nurses' job satisfaction. Journal of Nursing Management, 27(8), 1691-1699. https:// doi.org/10.1111/jonm. 12859

Godhardt, T. (2017). Reconciling the History of the Hangman's Noose and its Severity within Hostile Work En- vironment Claims. J. Marshall L. Rev., 51, 137.

Goldman, A. (2009). Destructive leaders and dysfunctional organizations: A therapeutic approach. Cambridge University Press.

Greitemeyer, T., \& Sagioglou, C. (2017). Increasing wealth inequality may increase interpersonal hostility: The relationship between personal relative deprivation and aggression. The Journal of Social Psychology, 157(6), 766-776. https://doi.org/10.1080/00224545.2 017.1288078

Hair Jr, J. F., Sarstedt, M., Ringle, C. M., \& Gudergan, S. P. (2017). Advanced issues in partial least squares structural equation modeling. Sage publications.

Heathfield, S. M. (2014). What makes a work environment hostile. Available at: https://www.thebalancecareers.com/what-makes-a-work-environment-hostile-1919363

Hellmich, D., \& Hellmich, L. (2019). Narcissistic Leadership: When Serving Self Eclipses Serving Mission. New Directions for Community Colleges, 185, 53-63. https://doi.org/10.1002/cc.20338

Hershcovis, M. S., \& Barling, J. (2010). Towards a multifoci approach to workplace aggression: A meta-analytic review of outcomes from different perpetrators. Journal of Organizational Behavior, 31(1), 24-44. https://doi.org/10.1002/job.621

Higgs, M.(2009). The good, the bad and the ugly: Leadership and narcissism. Journal of change management, 9(2), 165-178. https://doi.org/10.1080/14697010902879111

Holtzman, S., \& Vezzu, S. (2011). Confirmatory factor analysis and structural equation modeling of noncognitive assessments using PROC CALIS. NorthEast SAS Users Group (NESUG), 2011 proceedings, 11-14.

Huang, L., Krasikova, D. V., \& Harms, P. D. (2020). Avoiding or embracing social relationships? A conservation of resources perspective of leader narcissism, leader-member exchange differentiation, and follower voice. Journal of Organizational Behavior, 41(1), 7792. https://doi.org/10.1002/job.2423

Jacinto, C., Canoa, M., \& Soares, C. G. (2009). Workplace and organisational factors in accident analysis within the Food Industry. Safety Science, 47(5), 626-635. http://doi.org/10.1016/j.ssci.2008.08.002

Jørstad, J. (1996). Narcissism and leadership: Some differences in male and female leaders. Leadership \& Organization Development Journal, 17(6), 17-23. https:// doi.org/10.1108/01437739610130528

Judge, T. A., LePine, J. A., \& Rich, B. L. (2006a). Loving yourself abundantly: relationship of the narcissistic personality to self-and other perceptions of workplace deviance, leadership, and task and contextual performance. Journal of Applied Psychology, 91(4), 762. https://psycnet.apa.org/doi/10.1037/00219010.91.4.762

Judge, T. A., Scott, B. A., \& Ilies, R. (2006b). Hostili- 
ty, job attitudes, and workplace deviance: test of a multilevel model. Journal of Applied Psychology, 91(1), 126. https://psycnet.apa.org/doi/10.1037/00219010.91.1.126

Krsnik Horvat, B., \& Pagon, M. (2012). Attitudes toward workplace mobbing in Slovenian research organisations. Organizacija, 45(4). https://doi.org/10.2478/ v10051-012-0018-0

Lee, R. T., Brotheridge, C. M., Brees, J. R., Mackey, J., \& Martinko, M. J. (2013). An attributional perspective of aggression in organizations. Journal of Managerial Psychology, 28(3), 252-272. https://doi. org/10.1108/02683941311321150

Li, C., Sun, Y., Ho, M. Y., You, J., Shaver, P. R., \& Wang, Z. (2016). State narcissism and aggression: The mediating roles of anger and hostile attributional bias. $A g$ gressive Behavior, 42(4), 333-345.

Lyubykh, Z., Hershcovis, M. S., \& Turner, N. (2020). 20 Understanding the Role of Affect in Workplace Aggression. The Cambridge Handbook of Workplace Affect, 270. https://doi.org/10.1017/9781108573887.021

Malik, P., \& Lenka, U. (2018). Integrating antecedents of workplace deviance: utilizing AHP approach. Journal of Indian Business Research. https://doi.org/10.1108/ JIBR-09-2017-0148

Maneethai, D. (2019). Effects of a Hostile Work Environment on Production Deviance (Doctoral dissertation). University of Houston, 1-50. https://hdl.handle. net/10657/4685

Michel, J. S., \& Bowling, N. A. (2013). Does dispositional aggression feed the narcissistic response? The role of narcissism and aggression in the prediction of job attitudes and counterproductive work behaviors. Journal of Business and Psychology, 28(1), 93-105. https://doi. org/10.1007/s10869-012-9265-6

Mousa, M., Abdelgaffar, H. A., Aboramadan, M., \& Chaouali, W. (2020). Narcissistic leadership, employee silence, and organizational cynicism: A study of physicians in Egyptian public hospitals. International Journal of Public Administration, 1-10. https://doi.org $/ 10.1080 / 01900692.2020 .1758719$

Nevicka, B., De Hoogh, A. H., Den Hartog, D. N., \& Belschak, F. D. (2018). Narcissistic leaders and their victims: followers low on self-esteem and low on core self-evaluations suffer most. Frontiers in Psychology, 9, 422. https://doi.org/doi:10.3389/fpsyg.2018.00422

Nevicka, B., De Hoogh, A. H., Van Vianen, A. E., \& Ten Velden, F. S. (2013). Uncertainty enhances the preference for narcissistic leaders. European Journal of Social Psychology, 43(5), 370-380. https://doi. org/10.1002/ejsp.1943

Olson, B. J., Nelson, D. L., \& Parayitam, S. (2006). Managing aggression in organizations: what leaders must know. Leadership \& Organization Development Journal. https://doi.org/10.1108/01437730610677981
Ong, C. W., Roberts, R., Arthur, C. A., Woodman, T., \& Akehurst, S. (2016). The leader ship is sinking: A temporal investigation of narcissistic leadership. Journal of Personality, 84(2), 237-247. https://doi.org/10.1111/ jopy. 12155

Posthuma, R. A., Ramsey, J. R., Flores, G. L., Maertz, C., \& Ahmed, R. O. (2019). A risk management model for research on expatriates in hostile work environments. The International Journal of Human Resource Management, 30(11), 1822-1838. https://doi.org/10.1080/0 9585192.2017.1376222

Ramirez, J. M., \& Andreu, J. M. (2006). Aggression, and some related psychological constructs (anger, hostility, and impulsivity) Some comments from a research project. Neuroscience \& Biobehavioral Reviews, 30(3), 276-291. https://doi.org/10.1016/j.neubiorev.2005.04.015

Redondo, N., Peña, M. E., Graña, J. L., \& Andreu, J. M. (2017). Psychometric properties of the Aggression Questionnaire: A replication in a sample of partner-assaultive men in psychological treatment. Psicothema, 29(4), 584-589. https://doi.org/doi:10.7334/psicothema2016.390

Robinson, S. L., \& Bennett, R. J. (1995). A typology of deviant workplace behaviors: A multidimensional scaling study. Academy of Management Journal, 38(2), 555-572. https://doi.org/10.5465/256693

Rosenthal, S. A. (2006). Narcissism and leadership: A review and research agenda. http://hdl.handle. net/1721.1/55948

Rosenthal, S. A., \& Pittinsky, T. L. (2006). Narcissistic leadership. The leadership quarterly, 17(6), 617-633. https://doi.org/10.1016/j.leaqua.2006.10.005

Selden, M. P., \& Downey, R. G. (2012). Workplace hostility: Defining and measuring the occurrence of hostility in the workforce. Work, 42(1), https://doi.org/93-105. 10.3233/WOR-2012-1332

Semenyna S.W. (2018). Narcissism. In: Shackelford T., Weekes-Shackelford V. (eds) Encyclopedia of Evolutionary Psychological Science. Springer, Cham. https://doi.org/10.1007/978-3-319-16999-6_675-1

Tiwari, M. \& Jha, R. (2021), Narcissism, toxic work culture and abusive supervision: a double-edged sword escalating organizational deviance. International Journal of Organizational Analysis, ahead-of-print. https:// doi.org/10.1108/IJOA-05-2020-2187

Vance, C. M., Ensher, E. A., Hendricks, F. M., \& Harris, C. (2004). Gender-based vicarious sensitivity to disempowering behavior in organizations: Exploring an expanded concept of hostile working environment. Employee Responsibilities and Rights Journal, 16(3), 135-147. https://doi.org/10.1023/B:ERRJ.0000038649.75806.28

Walker, S. Y. (2018). Workplace Issues Part II: Am I in a Hostile Work Environment?. Teaching and Learning 
in Nursing, 13(4), 271-272. https://www.learntechlib. org $/ \mathrm{p} / 198597 /$

Wittmer, J. L., Sinclair, R. R., Martin, J. E., Tucker, J. S., \& Lang, J. (2013). Shared aggression concerns and organizational outcomes: The moderating role of resource constraints. Journal of Organizational Behavior, 34(3), 370-388. https://doi.org/10.1002/job.1807

Worley, V. B., \& Worley, R. M. (2020). Inmate public autoerotism and hostile work environments: an examination of federal cases. Journal of Crime and Justice, 1-15. https://doi.org/10.1080/0735648X.2020.1795902

Y1ld1z, B., \& Alpkan, L. (2015). A theoretical model on the proposed predictors of destructive deviant workplace behaviors and the mediator role of alienation. Procedia-Social and Behavioral Sciences, 210, 330-338. https://doi.org/10.1016/j.sbspro.2015.11.373

Zhang, P., Li, S., Liu, W., Han, Y., \& Muhammad, N. A. (2018). Exploring the role of moral disengagement in the link between perceived narcissistic supervision and employees' organizational deviance: A moderated mediation model. Asian Journal of Social Psychology, 21(4), 223-236. https://doi.org/10.1111/ajsp.12323

Hussein Hurajah Al Hasnawi: I have a master's degree from the University of AL-Qadisiyah, College of Administration and Economics in the field of production and operations management in the year 2005. I have also obtained a Ph.D. from the University of Kerbala,
College of Administration and Economics in the field of Organizational Behavior and Human Resources Management in 2015. I currently work at the University of Kerbala, College of Administration and Economics in the Business Administration Department. I have taught many subjects in my specialty, as well as in other specialties. I also have taught Human Resources Management, Knowledge Management, Strategic Information Systems, and Quality Management in postgraduate studies (Masters and Ph.D.). I have numerous research papers published in local and international journals.

Ali Abdulhassan Abbas: I have a master's degree from the University of Karbala College of Administration and Economics in the field of Production Management and Operations in the year 2005. I have also obtained a Ph.D. from Karbala University, College of Administration and Economics in Organizational Behavior and Human Resources Management in 2014. I currently work at Karbala University, College of Administration and Economics in the Accounting Department. I have taught many subjects in my specific area, as well as in other areas. I have also taught Financial Management for postgraduate studies. I have translated 4 books on business administration into Arabic. I have numerous research papers published in local and international journals. 